\title{
ПРАВОВОЙ РЕЖИМ ОРГАНОВ, ТКАНЕЙ И КЛЕТОК ЧЕЛОВЕКА ПОСЛЕ СМЕРТИ
}

\author{
Халабуденко О.А.
}

Аннотация: В работе анализируется правовой режим органов, тканей, клеток и тела человека. Проводится анализ действующего национального и международного законодательства, регулирующего вопросы трансплантации органов, тканей и клеток человека. На примере национального и международного законодательства демонстрируются особенности совершения актов частноправовых актов саи а тогтет. Отмечается, что телесную оболочку человека нельзя признать отдельньм самостоятельным объектом, поскольку при жизни человека она не существует сама по себе, а является неотьемлемой частью индивида. Метод или методология исследования: Для достижения цуели и решения задач, стоящзих перед исследованием были применены общенаучные и частно-научные методы, а именно: анализа, синтеза, структурно-логический метод, статистический, метод сравнительно-правового анализа метод от конкретного к абстрактному и иные методы научного познания. Автор утверждает, что права в отношении названных объектов относятся к особой группе прав sui genеris - соматических прав. Утверждается, что в отношении объектов этих прав действуют специиальный правовый режим. Отмечается, что права в отночении рассматриваемых объектов могут быть объектом частноправовых актов саиsа mortem с учетом специального правового режима, установленного по отношению к ним.

Ключевые слова: Правовой режим, смерть, соматические права, частноправовые акты, персонифицированный характер, телесная оболочка, цуелостность личности, трансплантация, донор, физическое лицуо.

Распоряжение органами, тканями и клетками человека при жизни и после смерти представляет собой частный случай реализации так называемых «соматических прав». В широком смысле эти права охватывают: свободу человека самостоятельно делать выбор между продолжением или прекращением своего физического существования, право человека относительно органов, тканей и клеток, возникающие у донора и реципиента, право распоряжения органами и тканями, удаленными в целях отличных от целей донорства, репродуктивные и сексуальные права и т.д. Выделение названной группы прав основывается на представлении о том, что каждый человек вправе самостоятельно распоряжаться своим телом. Эти права имеют персонифицированный характер, они не отчуждаемы от правообладателя.

Отметим, что телесную оболочку человека нельзя признать отдельным самостоятельным объектом, поскольку при жизни человека она не существует сама по себе, а является неотъемлемой частью индивида. Физическое лицо не является собственником тела до тех пор, пока тело олицетворяет лицо[1]. Соответственно, пользование и распоряжение физическим лицом своим организмом происходит не путем осуществления правомочий собственника, а посредством совершения иных правомерных действий по осуществлению права на физическую неприкосновенность. Последнее, наряду с правом на психическую неприкосновенность, составляет единое неимущественное по 
своей природе право на целостность личности. Физическая неприкосновенность предполагает автономное решение физическим лицом вопросов, связанных с его телом, а также отделенными от организма органами, тканями и клетками. В свою очередь психическая неприкосновенность свободное совершение поступков в соответствии со своим сознанием и волей[2]. Таким образом, после заключения, например, договора донорства или в результате совершения одностороннего акта о распоряжении органом на случай смерти, объектом будет физическая неприкосновенность лица, рассматриваемая как компонента права на целостность личности. Наряду с правом на жизнь, право на целостность личности относится к основополагающим конституционным правам. В соответствии с ч. (1) ст. 24 Конституции Республики Молдова[3] государство гарантирует каждому человеку право на жизнь и на физическую и психическую неприкосновенность.

Право на целостность личности закреплено в ст. 3 Хартии об основных правах Европейского Союза[4] (далее - Хартия), согласно которой каждый человек имеет право на собственную физическую и психическую целостность. При этом Хартией признается, что в области медицины и биологии необходимо обеспечить, в частности: добровольное и свободное согласие заинтересованного лица в соответствии с установленным законом порядком; запрещение евгенической практики, прежде всего той, которая направлена на селекцию человека; запрещение использования тела человека и его частей как таковых в качестве источника финансовой выгоды; запрещение репродуктивного клонирования человеческих существ.

Интересующие нас соматические права, будучи составной частью права на целостность личности, относятся к телу организма. Сам термин «сома» (от др. - греч. $\sigma \tilde{\omega} \mu \alpha-$ тело) был введен в науку немецким зоологом А. Вейсманом в XIX в. для обозначения тела организма («смертной части»), в противоположность зародышевой плазме, передающейся из поколения в поколение через половые клетки. Из деления организма на соматическую составляющую и зародышевую плазму (наследственное вещество) следует справедливое утверждение о принципиальной невозможности наследования свойств, приобретаемых организмами под влиянием условий жизни в процессе их индивидуального развития[5]. В настоящее время прилагательное «соматический» широко применяется для обозначения телесных явлений в отличие от явлений психического характера. Данный тер- мин получили распространение в научной сфере (например, в медицине традиционно выделяются соматические и психические заболевания, в биологии соматология занимается вопросами исследования человеческого тела) и т.д. Использование понятия «соматические права» в юридической науке признается дискуссионным[6].

Выделение в составе соматических прав, наряду с неприкосновенностью психики, права на физическую неприкосновенность восходит к традиционной для европейской культуры дихотомии тела и души, а точнее - к известному конфликту между идейными течениями, отвергавшими благость телесного начала, и учениями, рассматривающими corpus как благо, которое, следовательно, с юридической точки зрения способно быть объектом субъективного права, поскольку оно подчинено воле лица[7]. Признание телесного начала благом позволяет утверждать, что право на физическую неприкосновенность есть социальное благо, которым его обладатель волен распоряжаться, и что это право выступает объектом правовой охраны (защиты).

По своей природе это права - sui generis, их объектами служат органы, ткани и клетки человека. Следует согласиться с мнением исследователей, считающих целесообразным выделить несколько групп органов, тканей и клеток человека, положив в основу деления причину их отторжения (отчуждения) и цель дальнейшего использования[8]. Первую группу составляют трансплантаты - органы, ткани и клетки, которые изымаются в медицинских целях для дальнейшей пересадки. Забор этих органов и тканей влечет временное или постоянное ухудшение состояния здоровья и (или) риск такого ухудшения. По поводу трансплантатов могут быть заключены договоры донорства, комплексные договоры хранения и дальнейшей пересадки; оформляются односторонние распорядительные акты по распоряжению телом после смерти. Частноправовые акты [9] в отношении трансплантатов не направлены на приобретение имущественных прав и не являются актами по отчуждению имущественных прав. Однако донор вправе получить вознаграждение, размер которого ограничивается покрытием расходов и неудобств, причиненных ему, в частности: на возмещение потерь доходов и других обоснованных расходов живых доноров, вызванных донорством или связанными с ним медицинскими обследованиями, а также выплату обоснованных расходов на законные медицинские или технические услуги, связанные с донорством. Ко второй группе следует отнести органы и ткани, отчуждаемые в результате оказания медицинской 
помощи. К ним относятся, например, ампутированные по причине заболевания или травмы части тела пациента. Наконец, третью группу составляют органы и ткани, отторжение которых не связано с заболеванием и (или) медицинским вмешательством и может не иметь определенной цели дальнейшего использования. К этой группе можно отнести, например, остриженные волосы.

Представляется, что любые органы, ткани и клетки человека с момента их отделения от организма, а также тело (прах) после смерти - это объекты материального мира, относящиеся к категории вещей со специальным правовым режимом[10]. «Неотделенные же части человеческого тела, составляя принадлежность личности, не могут подчиняться чужой власти» [11], а следовательно, не могут рассматриваться в качестве объектов прав. Правопорядок не признает право на чужое тело или на отдельные его части до момента их отделения от тела.

Одной из форм реализации права на физическую неприкосновенность является право человека относительно его органов, тканей и клеток. Согласно Закону о трансплантации органов, тканей и клеток человека[12] (далее - Закон о трансплантации), органом является жизненно важная отдельная часть человеческого тела, сформированная из различных тканей, которые поддерживают ее структуру, васкуляризацию и выполняют физиологические функции со значительной степенью автономии. Это та часть тела человека, которая, будучи полностью удалена, не может быть воспроизведена организмом человека. Тканями признаются все части (анатомические образования) человеческого тела, сформированные из клеток, в свою очередь клетками - отдельные клетки или конгломерат клеток, не связанные каким бы то ни было видом ткани. Органы, ткани и клетки человека используются для трансплантации (пересадки) от донора реципиенту в лечебных и других определенных законом целях.

Вопросам трансплантации посвящены, в частности, Конвенция о защите прав и достоинства человека в связи с применением достижений биологии и медицины: Конвенция о правах человека и биомедицине[13] (далее - Конвенция), совершенная в Овьедо 4 апреля 1997 года и Дополнительный протокол к Конвенции о правах человека и биомедицине относительно трансплантации органов и тканей человека[14] (далее - Протокол), подписанный в Страсбурге 25 января 2005 года. Указанные акты действуют в отношении государств - членов Совета Европы, Европейского Союза и иных Государств, присоединившихся к ним. Основная цель Конвенции состоит в принятии ее сторонами обязанности защиты достоинства человека и гарантии каждому без исключения соблюдение целостности личности и других прав и основных свобод в связи с применением достижений биологии и медицины. Протокол применяется в отношении трансплантации органов, тканей и клеток человеческого происхождения.

Трансплантация в соответствии с Законом о трансплантации является медицинской деятельностью, имеющая целью восстановление функции человеческого организма путем пересадки органов, тканей и клеток от донора реципиенту. Трансплантация может производиться от одного лица другому (аллогенная) или собственными клетками, тканями и органами (аутогенная). Термин «аллогенная трансплантация» означает полный процесс удаления органа или ткани у одного лица и имплантацию этого орган или ткани другому лицу, включая все процедуры по подготовке, сохранности и хранению. Речь идет об удалении органов и тканей из организма родившегося человека, живого или умершего на момент операции, и имплантации органов и тканей человеческого происхождения другому человеку, который также уже родился. Аллогенная трансплантация возможна как от живого, так и от мертвого донора, а также от лица, проходящего медицинские процедуры для своего блага, давшего свое согласие на имплантацию своего удаленного органа другому лицу. Трансплантация определяется как целостный процесс, начинающийся с удаления органа или ткани у одного человека и заканчивающийся имплантацией данного органа или ткани другому человеку. Человек, у которого удалили материал, называется «донором», а человек, которому материал имплантирован, - «реципиентом» [15]. Таким образом, донором выступает лицо, которое отдает один или несколько органов, ткани и (или) клетки для терапевтического использования. Рецепиентом (получателем) признается лицо, которому производится пересадка органов, и (или) тканей, и (или) клеток донора. Донорство может быть осуществлено при жизни данного лица или после смерти.

Конвенция, Протокол, равно как и национальное законодательство, регулирующее вопросы трансплантации, не применяется в отношении половых органов и тканям, служащим передаче генетического материала, эмбриональным органам и тканям и органам и тканям плода, в том числе эмбриональным стволовым клеткам. Дело в том, что трансплантация таких органов и тканей представляется имеющей последствия, отличные от последствий репродукции с использованием медицинских методов, и регулируется специаль- 
ными правилами. В соответствии с Законом о репродуктивном здоровье[16] донорство половых клеток и эмбрионов представляет собой медицинскую технологию, посредством которой лицо предоставляет свои гаметы (сперматозоиды или яйцеклетки) либо эмбрионы другим лицам для наступления беременности. Право быть донорами половых клеток (сперматозоидов, яйцеклеток) и эмбрионов имеют мужчины и женщины в возрасте от 18 до 40 лет, соматически и психически здоровые, прошедшие соответствующее медико-генетическое обследование. Доноры половых клеток и эмбрионов не принимают на себя родительские обязанности по отношению к будущему ребенку и не несут ответственности за него. Они не вправе выяснять личность ребенка и его родителей. Донорство половых клеток и эмбрионов осуществляется при наличии добровольного письменного информированного согласия донора (доноров), которое должно содержать описание особенностей предстоящей медицинской процедуры, сведения о возможном риске, побочных эффектах и осложнениях, правовые последствия донорства.

Конвенция, Протокол, равно как и национальное законодательство, действующее в рассматриваемой сфере, не применяются к донорству крови и ее производным материалам, включая кровь и продукты, полученные из крови для использования при лечении переливанием крови в трансфузийной медицине. Таким образом, переливание крови и использование производных от крови продуктов регулируются специальным нормативно-правовыми актами. Согласно Закону о донорстве и переливании крови [17] донорство крови и ее компонентов является добровольным и безвозмездным актом. Донор крови и ее иммунных и изоиммунных компонентов, осуществляющий донорство после предварительной инокуляции соответствующих антигенов, имеет право на денежное вознаграждение, выплачиваемое в размере и порядке, установленном правительством.

Имплантация в традиционном понимании не включает использования тканей человеческого происхождения в форме медицинских препаратов или фармацевтической продукции. Не являются объектами трансплантации волосы, ногти, плацента и продукты жизнедеятельности человека.

Аллогенная трансплантация осуществляется при соблюдении специальных правил, установленных законом. Отметим, что особый правовой режим органов, тканей и клеток человека предполагает установление специального режима их распределения. Такое распределение должно производиться в соответствии с медицинскими критериями. Данное понятие следует толковать в широком смысле в свете соответствующих профессиональных стандартов и обязательств и как распространяющееся на любую ситуацию, способную повлиять на состояние здоровья пациента, качество трансплантируемого материала или результаты трансплантации. В частности, при распределении должно учитываться совместимость органа или ткани с организмом реципиента, медицинская неотложность, время на транспортировку органа, время нахождения на листе ожидания, те или иные трудности в поиске подходящего органа для некоторых пациентов (например, пациентов с высокой степенью иммунизации или редкими характеристиками тканей) и ожидаемые результаты трансплантации.

Органы, удаленные у умерших лиц, должны предоставляться только пациентам, стоящим в официальном листе ожидания (данное требование не обязательно в отношении тканей). Закон о трансплантации предусматривает, что органы, ткани и клетки распределяются пациентам согласно листу ожидания в соответствии с правилами распределения. В случае отсутствия в списках совместимого получателя Агентство по трансплантации разрешает передачу органа, тканей, клеток другому признанному на национальном или международном уровне учреждению трансплантации, с которым оно заключило двусторонние соглашения. Агентство по трансплантации наделяется исключительным правом разрешать на основе двусторонних международных соглашений обмен органами, тканями и клетками для трансплантации и принимает все возможные меры, чтобы они соответствовали стандартам качества и безопасности.

Протоколом установлено правило, что система трансплантации должна предусматривать сбор и запись информации, требующейся для обеспечения отслеживания органов и тканей. Другими словами, организация трансплантации должна обеспечивать возможность отслеживания пути всех органов или тканей от донора к реципиенту. В пояснительном докладе к Протоколу отмечается, что это необходимое требование, поскольку невозможно полностью предотвратить риск передачи заболевания от донора к реципиенту и заражение законсервированного материала. Более того, могут появиться новые заболевания или риски их возникновения. Таким образом, как в целях общественного здравоохранения, так и по причине необходимости информировать доноров или реципиентов о потенциальных проблемах, которые могут возникнуть после трансплантации, важно иметь возможность проследить 
путь любого трансплантируемого материала от донора к реципиенту и наоборот. Если передаваемое заболевание было обнаружено у реципиента не в самом начале, а позднее, необходимо найти доноров для определения источника заражения и отозвать неиспользованные продукты. При получении согласия, как доноры так и реципиенты должны быть предупреждены о таких долгосрочных последствиях трансплантации и возможной необходимости продолжительного наблюдения. Кроме того, может возникнуть необходимость в анализе того, как использовались органы и ткани, для определения незаконного или неэтичного использования такого материала, предотвращения незаконной торговли органами и тканями и валидации системы распределения. В этих целях система трансплантации должна предусматривать всеобъемлющую систему, позволяющую отслеживать весь трансплантируемый материал, без ущерба для положений о конфиденциальности[18].

Удаление органов и тканей у умерших физических лиц имеет свои, урегулированные правом особенности. В частности, органы и ткани не могут быть удалены у умершего лица, если это лицо не признано умершим в соответствии с законодательством (ст. 16 Протокола). Закон о трансплантации предусматривает, что органы, ткани и клетки могут быть изъяты у умершего лица лишь в случае констатации смерти согласно критериям, установленным Министерством здравоохранения. Таким образом, смерть лица должна быть засвидетельствована до того, как органы или ткани могут быть удалены в соответствии с законом. Известные сложности вызывает определение конкретной процедуры декларирования смерти, в то время как основные функции человека искусственно поддерживаются. В соответствии со ст. 11 Закона о трансплантации смерть должна быть констатирована одним из следующих способов:

- в случае полной и необратимой сердечно-дыхательной остановки у человека с нормальной или близкой к нормальной температурой смерть констатируется при проведении в течение не менее пяти минут всех реанимационных мероприятий, на протяжении которых все тесты однозначно показывают отсутствие кровоснабжения мозга и жизненно важных органов;

- у лица с необратимыми изменениями в жизненно важных центрах мозга при искусственной поддержке сердечно-дыхательной функции смерть констатируется специальными тестами (критериями), утвержденными Министерством здравоохранения.
Факт наступления смерти подтверждается врачами в рамках принятой процедуры, и только такая форма засвидетельствования смерти может сделать возможной процедуру трансплантации. Группа медиков, занимающаяся удалением, должна удостовериться, что требуемая процедура была выполнена, до начала операции по удалению. Данная процедура засвидетельствования смерти отлична от формальной выдачи свидетельства о смерти. Важной защитной мерой для засвидетельствования смерти служит требование того, чтобы группа врачей, констатирующих смерть, была отлична от группы, участвующей в процессе трансплантации на каких-либо стадиях. Согласно ст. 12 закона о трансплантации врачи, констатирующие смерть потенциального донора, должны быть иными, нежели врачи, которые непосредственно участвуют в изъятии какого-либо органа, ткани или клетки у умершего лица, участвуют в последующих процедурах трансплантации или несут ответственность за потенциального получателя.

Для удаления органов, тканей и клеток после смерти принципиальное значение имеет согласие потенциального донора или разрешение иных указанных в законе лиц. Руководящими принципами ВОЗ по трансплантации человеческих клеток, тканей и органов[19] предусмотрено, что для проведения трансплантации клетки, ткани и органы могут быть изъяты из тел умерших в случае, если получено согласие в форме, требуемой законом, и если нет оснований полагать, что умершее лицо возражало против такого изъятия.

Обратим внимание, что в зависимости от социальных, медицинских и культурных традиций каждой страны, а также от того, каким образом семьи участвуют в процессе принятия решений относительно своего здоровья в целом, согласие на получение органов и тканей от умерших может быть «четко выраженным» или «предполагаемым». В обеих системах любое надежное свидетельство неприятия человеком посмертного изъятия его клеток, тканей или органов воспрепятствует такому изъятию. В системе четко выраженного согласия, которую иногда называют системой «презумпции несогласия» (“opting in”), клетки, ткани и органы могут быть изъяты из тела умершего в случае, если умершим при жизни было недвусмысленно заявлено согласие на такое изъятие. В зависимости от существующего в стране закона изъявление согласия допускается в устной форме или может быть зафиксировано в карте донора, водительских правах или удостоверении личности, либо в медицинской карте или в реестре доноров. В 
случае, если умерший при жизни не оставил ни положительного, ни четко отрицательного отношения к изъятию органа, разрешение должно быть получено от уполномоченного в правовом порядке лица, каковым обычно является член семьи[20].

Протокол (ст. 17) прямо предусматривает, что органы и ткани не удаляются у умершего лица, если требующееся в соответствии с законодательством согласие или разрешение на такое удаление не будет получено. Удаление не может быть осуществлено, если умершее лицо возражало против этого. В соответствии со ст. 13 Закона о трансплантации изъятие органа (ткани, клеток) у умершего для целей трансплантации возможно в случае наличия предсмертного согласия умирающего, выраженного в соответствии с законом. Во всяком случае, не допускается изъятие ни в какой форме, если при жизни умершее лицо выразило возражение против донорства посредством собственноручно написанного или иного законно составленного акта отказа. Однако при отсутствии согласия донорство возможно, если не имеется письменного возражения против донорства со стороны хотя бы одного из совершеннолетних членов семьи, других родственников первой степени родства или законного представителя умершего. Наконец, закон о трансплантации предусматривает, что донорство возможно без согласия близких родственников или законного представителя, если после законной констатации смерти никто из близких родственников или законный представитель не обратились с целью выражения мнения в отношении донорства, а сведения о близких родственниках или законном представителе умершего отсутствуют.

Другая система, которая является системой предполагаемого согласия, - иначе ее называют «презумпцией согласия» (“opting (or contracting) $o u t$ ”) - позволяет осуществить изъятие материала из тела умершего для трансплантации (и в ряде стран - для анатомического изучения либо в научных целях) в случае, если умерший при жизни не выразил своего возражения против изъятия органа, которое должно быть зафиксировано в официальном документе в установленном порядке, или в случае, если информированная сторона не поставит в известность о возражении, высказанном при жизни умершим против изъятия органа для трансплантации[21]. Принцип презумпции согласия узаконен, в частности, в Российской Федерации. Так, согласно ст. 8 Закона РФ «О трансплантации органов и (или) тканей человека» [22] изъятие органов и (или) тканей у трупа не допускается, если учреждение здравоохранения на момент изъятия поставлено в известность о том, что при жизни данное лицо либо его близкие родственники или законный представитель заявили о своем несогласии на изъятие его органов и (или) тканей после смерти для трансплантации реципиенту. Очевидно, что для реализации «презумпции согласия» в случае отсутствия выраженных или имплицитных возражений против донорства должна быть предусмотрена соответствующая процедура намерений, отраженных в соответствующем реестре возражений, выраженных потенциальными донорами.

Во всяком случае, независимо от системы, если имеются сомнения в отношении воли умершего, группа врачей, ответственная за удаление органов, должна сначала предпринять попытку получения свидетельства родственников умершего. Если национальное законодательство не предусматривает обратного, такое разрешение не должно зависеть от предпочтений самих ближайших родственников в отношении донорства органов и тканей. Ближайшим родственникам должны быть заданы вопросы только о выраженных или предполагаемых пожеланиях умерших лиц. Решающим фактором при решении вопроса об удалении органов или тканей являются выраженные взгляды потенциального донора. Стороны должны четко определить, может ли быть произведено удаление органа или ткани, если пожелания умершего неизвестны и не могут быть определены на основании опроса родственников или друзей[23].

Органы, ткани и клетки умершего не могут выступать объектом купли-продажи или иной материально-правовой сделки, совершаемой его близкими родственниками. Имущественная компенсация таким лицам запрещена. Таким образом, закон прямо запрещает торговлю органами, тканями и клетками человека, а также получение финансовой выгоды или преимуществ от торговли телом человека и его частями. Торговля органами, тканями и клетками человека признается преступлением и преследуется в соответствии с уголовным законодательством. Законом также запрещена пропаганда необходимости трансплантации органов, тканей и (или) клеток с целью предложения или получения финансовой выгоды или преимуществ, связанных с этим. Руководящими принципами ВОЗ по трансплантации человеческих клеток, тканей и органов отмечается, что идея оплаты клеток, тканей и органов чревата опасностью недобросовестного использования беднейших и наиболее уязвимых групп населения, при этом подрывается идея безвозмездного донорства, что в конечном итоге ведет 
к спекуляции и торговле людьми. Подобные выплаты подразумевают, что некоторые люди лишены достоинства и являются всего лишь объектами для использования другими[24].

Изъятие органов (тканей, клеток) должно совершаться с учетом уважения к телу умершего. Закон обязывает врачей, осуществивших изъятие органов, тканей и клеток у умершего, произвести реставрацию трупа и его лица с применением специальных методов и средств, в том числе при необходимости хирургических, с целью придания достойного вида телу умершего (ст. 14 Закона о трансплантации).
Итак, распорядительные действия, совершаемые физическим лицом в отношении своих органов, тканей и клеток на случай смерти, представляют собой форму реализации права на целостность личности. Осуществление распорядительных действий в отношении органов, тканей и клеток человека регламентировано специальными нормативно-правовыми актами, устанавливающими особую процедуру реализации названных действий, осуществляемую в рамках трансплантационных процедур, исключающую возможность получения имущественной выгоды от их совершения.

\section{Библиография:}

1. Charter of Fundamental Rights of the European Union (2000/C 364/01)// Official Journal of the European Communities, 18.12.2000.

2. Ovidiu Ungureanu, Călina Jugastru. Drept civil. Persoanele. - Bucureşti, 2003. P. 29.

3. БСЭ, 1969-1978 гг. [электронный ресурс]// режим доступа: http://bse.sci-lib.com/article104448.html (дата доступа: 21.12.2014); Лаврик М.А. К теории соматических прав человека//Сибирский юридический вестник. 2005. № 3. С.18.

4. Дополнительный протокол к Конвенции о правах человека и биомедицине в области биомедицинских исследований [электронный ресурс] //режим доступа: http://conventions.coe.int/Treaty/rus/Treaties/ Html/195.htm (дата доступа: 21.12.2014).

5. Закон о донорстве и переливании крови Nr. 241 от 20.11.2008 // Monitorul Oficial от 13.01.2009. Nr. 1-2, статья № 2 .

6. Закон о репродуктивном здоровье Nr. 138 от 15.06.2012 // Monitorul Oficial от 28.09.2012. Nr. 205-207, статья № 673.

7. Закон Российской Федерации «О трансплантации органов и (или) тканей человека» № 4180-1 от 22 декабря 1992 года (в редакции Федеральных законов от 20.06.2000 № 91-Ф3, от 16.10.2006 № 160-Ф3, от 09.02.2007 № 15-Ф3)

8. Конвенция о защите прав и достоинства человека в связи с применением достижений биологии и медицины: Конвенция о правах человека и биомедицине [электронный ресурс]/The Treaty of Lisbon amending the Treaty on European Union and the Treaty establishing the European Community entered into force on 1 December 2009//http://conventions.coe.int/Treaty/rus/Treaties/Html/164.htm (дата доступа: 21.12.2014).

9. Конституция Республики Молдова от 29.07.1994// Monitorul Oficial Nr. 1 от 12.08.1994, статья № 1.

10. Коркунов Н.М. Лекции по общей теории права /Н. М. Коркунов; [сост., автор вступ. ст., коммент. А. Н. Медушевский]. - М.: Российская политическая энциклопедия (РОССПЭН), 2010. С. 157.

11. Малеина М.Н. Личные неимущественные права граждан: понятие, осуществление, защита. 2-е изд., испр. и доп. - М., 2001. С. 86-87.

12. Малеина М.Н. Статус органов, тканей, тела человека как объектов права собственности и права на физическую неприкосновенность.// «Законодательство», 2003. № 11, ноябрь. С. 22-49.

13. Пояснительный доклад к Дополнительному протоколу к Конвенции о правах человека и биомедицине относительно трансплантации органов и тканей человека // http:/conventions.coe.int/Treaty/rus/ Reports/Html/186.htm

14. Пояснительный доклад к Дополнительному протоколу к Конвенции о правах человека и биомедицине относительно трансплантации органов и тканей человека [электронный ресурс]// режим доступа: http://conventions.coe.int/Treaty/rus/Reports/Html/186.htm (дата доступа: 21.12.2014).

15. Пояснительный доклад к Дополнительному протоколу к Конвенции о правах человека и биомедицине относительно трансплантации органов и тканей человека [электронный ресурс]// режим доступа: http://conventions.coe.int/Treaty/rus/Reports/Html/186.htm (дата доступа: 21.12.2014). 
16. Руководящие принципы ВОЗ по трансплантации человеческих клеток, тканей и органов. УТверждены на Шестьдесят третьей сессии Всемирной ассамблеи здравоохранения в мае 2010 г., резолюция WHA 63.22 [электронный ресурс]//режим доступа: http://www.who.int/transplantation/ Guiding_PrinciplesTransplantation_WHA63.22ru.pdf (дата доступа: 21.12.2014).

17. Руководящие принципы ВОЗ по трансплантации человеческих клеток, тканей и органов. Утверждены на Шестьдесят третьей сессии Всемирной ассамблеи здравоохранения в мае 2010 г., резолюция WHA 63.22 [электронный ресурс]//режим доступа: http://www.who.int/transplantation/ Guiding_PrinciplesTransplantation_WHA63.22ru.pdf (дата доступа: 21.12.2014).

18. См., например: Крусс В. И. Личностные («соматические») права человека в конституционном и философско-правовом измерении: к постановке проблемы // Государство и право. 2000. № 10. С. 43.; Крусс В. И. Соматические права человека в соотношении православной антропологии С. Л. Франка и философии экологического кризиса В. Хесле //Медицина, этика, религия и право: материалы конф. М., 2000. С. 171-189; Крусс В. И. Актуальные аспекты проблемы злоупотребления правами и свободами человека // Государство и право. 2002. № 7. С. 46-53; Крусс В. И. К теории пользования конституционными правами // Государство и право; Дмитриев Ю. А. [Отклики] // Государство и право. 2003. № 1. С. 126 - 127; Лаврик М.А. К теории соматических прав человека Сибирский юридический вестник. 2005. № 3. С. 16-26; Лаврик М.А. Конституционные основания соматических прав человека: вопросы теории и практики зарубежных государств//Сибирский юридический вестник. 2006. №1. C.44-62.

19. Халабуденко О.А. Имущественные права. Книга 1. Вещное право. Кишинев, 2011. С. 26).

20. Халабуденко О.А. Имущественные права. Книга 1. Вещное право. С. 74-75.

\section{References (transliterated):}

1. Charter of Fundamental Rights of the European Union (2000/C 364/01)// Official Journal of the European Communities, 18.12.2000.

2. Ovidiu Ungureanu, Călina Jugastru. Drept civil. Persoanele. - Bucureşti, 2003. P. 29.

3. BSE, 1969-1978 gg. [elektronnyi resurs]// rezhim dostupa: http://bse.sci-lib.com/article104448.html (data dostupa: 21.12.2014); Lavrik M.A. K teorii somaticheskikh prav cheloveka//Sibirskii yuridicheskii vestnik. 2005. № 3. S.18.

4. Dopolnitel'nyi protokol k Konventsii o pravakh cheloveka i biomeditsine v oblasti biomeditsinskikh issledovanii [elektronnyi resurs] //rezhim dostupa: http://conventions.coe.int/Treaty/rus/Treaties/Html/195.htm (data dostupa: 21.12.2014).

5. Zakon o donorstve i perelivanii krovi Nr. 241 ot 20.11.2008 // Monitorul Oficial ot 13.01.2009. Nr. 1-2, stat'ya № 2 .

6. Zakon o reproduktivnom zdorov'e Nr. 138 ot 15.06.2012 // Monitorul Oficial ot 28.09.2012. Nr. 205-207, stat'ya № 673 .

7. Zakon Rossiiskoi Federatsii «O transplantatsii organov i (ili) tkanei cheloveka» № 4180-1 ot 22 dekabrya 1992 goda (v redaktsii Federal'nykh zakonov ot 20.06.2000 № 91-FZ, ot 16.10.2006 № 160-FZ, ot 09.02.2007 № 15-FZ)

8. Konventsiya o zashchite prav i dostoinstva cheloveka v svyazi s primeneniem dostizhenii biologii i meditsiny: Konventsiya o pravakh cheloveka i biomeditsine [elektronnyi resurs]/The Treaty of Lisbon amending the Treaty on European Union and the Treaty establishing the European Community entered into force on 1 December 2009//http://conventions.coe.int/Treaty/rus/Treaties/Html/164.htm (data dostupa: 21.12.2014).

9. Konstitutsiya Respubliki Moldova ot 29.07.1994// Monitorul Oficial Nr. 1 ot 12.08.1994, stat'ya № 1.

10. Korkunov N.M. Lektsii po obshchei teorii prava /N. M. Korkunov; [sost., avtor vstup. st., komment. A. N. Medushevskii]. - M.: Rossiiskaya politicheskaya entsiklopediya (ROSSPEN), 2010. S. 157.

11. Maleina M.N. Lichnye neimushchestvennye prava grazhdan: ponyatie, osushchestvlenie, zashchita. 2-e izd., ispr. i dop. - M., 2001. S. 86-87.

12. Maleina M.N. Status organov, tkanei, tela cheloveka kak ob"ektov prava sobstvennosti i prava na fizicheskuyu neprikosnovennost'.// «Zakonodatel’stvo», 2003. № 11, noyabr’. S. 22-49. 
13. Poyasnitel'nyi doklad k Dopolnitel'nomu protokolu k Konventsii o pravakh cheloveka i biomeditsine otnositel'no transplantatsii organov i tkanei cheloveka // http://conventions.coe.int/Treaty/rus/Reports/ Html/186.htm

14. Poyasnitel'nyi doklad k Dopolnitel'nomu protokolu k Konventsii o pravakh cheloveka i biomeditsine otnositel'no transplantatsii organov i tkanei cheloveka [elektronnyi resurs]// rezhim dostupa: http://conventions.coe.int/Treaty/rus/Reports/Html/186.htm (data dostupa: 21.12.2014).

15. Poyasnitel'nyi doklad k Dopolnitel'nomu protokolu k Konventsii o pravakh cheloveka i biomeditsine otnositel'no transplantatsii organov i tkanei cheloveka [elektronnyi resurs]// rezhim dostupa: http://conventions.coe.int/Treaty/rus/Reports/Html/186.htm (data dostupa: 21.12.2014).

16. Rukovodyashchie printsipy VOZ po transplantatsii chelovecheskikh kletok, tkanei i organov. Utverzhdeny na Shest'desyat tret'ei sessii Vsemirnoi assamblei zdravookhraneniya v mae 2010 g., rezolyutsiya WHA 63.22 [elektronnyi resurs]//rezhim dostupa: http://www.who.int/transplantation/Guiding_PrinciplesTransplantation_WHA63.22ru.pdf (data dostupa: 21.12.2014).

17. Rukovodyashchie printsipy VOZ po transplantatsii chelovecheskikh kletok, tkanei i organov. Utverzhdeny na Shest'desyat tret'ei sessii Vsemirnoi assamblei zdravookhraneniya v mae 2010 g., rezolyutsiya WHA 63.22 [elektronnyi resurs]//rezhim dostupa: http://www.who.int/transplantation/Guiding_PrinciplesTransplantation_WHA63.22ru.pdf (data dostupa: 21.12.2014).

18. Sm., naprimer: Kruss V. I. Lichnostnye («somaticheskie») prava cheloveka v konstitutsionnom i filosofskopravovom izmerenii: $k$ postanovke problemy // Gosudarstvo i pravo. 2000. № 10. S. 43.; Kruss V. I. Somaticheskie prava cheloveka v sootnoshenii pravoslavnoi antropologii S. L. Franka i filosofii ekologicheskogo krizisa V. Khesle //Meditsina, etika, religiya i pravo: materialy konf. M., 2000. S. 171-189; Kruss V. I. Aktual'nye aspekty problemy zloupotrebleniya pravami i svobodami cheloveka // Gosudarstvo i pravo. 2002. № 7. S. 46-53; Kruss V. I. K teorii pol'zovaniya konstitutsionnymi pravami // Gosudarstvo i pravo; Dmitriev Yu. A. [Otkliki] // Gosudarstvo i pravo. 2003. № 1. S. 126 - 127; Lavrik M.A. K teorii somaticheskikh prav cheloveka Sibirskii yuridicheskii vestnik. 2005. № 3. S. 16-26; Lavrik M.A. Konstitutsionnye osnovaniya somaticheskikh prav cheloveka: voprosy teorii i praktiki zarubezhnykh gosudarstv//Sibirskii yuridicheskii vestnik. 2006. №1. S.44-62.

19. Khalabudenko O.A. Imushchestvennye prava. Kniga 1. Veshchnoe pravo. Kishinev, 2011. S. 26).

20. Khalabudenko O.A. Imushchestvennye prava. Kniga 1. Veshchnoe pravo. S.74-75. 